\title{
Microrrelevo e a distribuição de frações granulométricas em Cambissolos de origem calcária ${ }^{1}$
}

\author{
Microrelief and particle-size fraction distribution in calcareous Inceptisols
}

\author{
Daniel Pontes de Oliveira ${ }^{2 *}$, Tiago Osório Ferreira ${ }^{3}$, Ricardo Espíndola Romero ${ }^{3}$, Paulo Roberto Silva Farias ${ }^{4}$ \\ Mirian Cristina Gomes Costa ${ }^{3}$
}

\begin{abstract}
RESUMO - A Chapada do Apodi caracteriza-se como importante pólo agrícola no estado do Ceará. Apesar da homogeneidade de clima, relevo e material de origem, seus solos apresentam grande variabilidade de atributos, muitas vezes em pequenas escalas espaciais, indicando a necessidade de manejos distintos. O presente trabalho teve como objetivo estudar a influência do microrrelevo na variabilidade espacial das diferentes frações granulométricas dos solos da Chapada do Apodi. Para isso, foi realizado levantamento planialtimétrico em uma área de 102 ha, seguido de tradagens para coleta das amostras de solo e determinação da profundidade efetiva. As amostras foram submetidas à análise granulométrica e os dados foram tratados por meio da estatística descritiva e da geoestatística, utilizando-se semivariogramas e mapas de krigagem. Com base nas formas de microrelevo, o local de estudo foi compartimentado em 03 superfícies distintas (côncava, convexa e retilínea). Por meio dos resultados foi identificada clara influência do microrrelevo na distribuição das frações granulométricas. Maiores teores de argila e maiores profundidades de solos foram encontrados na superfície côncava. Estes resultados são indicativos de maior ação da pedogênese nos solos desta porção do terreno em resposta à existência de fluxos hídricos convergentes. A ocorrência de maiores teores de areia e solos mais rasos na superfície convexa e mais elevada indica menor ação da pedogênese e maior intensidade do processo de erosão seletiva. $\mathrm{O}$ uso da geoestatística contribuiu para a identificação de áreas com necessidades diferenciadas de manejo, servindo como importante ferramenta para a tomada de decisões, especialmente relacionadas à irrigação.
\end{abstract}

Palavras-chave: Chapada do Apodi. Variabilidade Espacial. Microtopografia. Solos-análise.

\begin{abstract}
The Apodi Plateau is characterized as an important agricultural centre for the state of Ceará, Brazil. Despite the homogeneity of climate, topography and parent material, soils in the area exhibit a great variability in attributes, often on small spatial scales, indicating the need for separate managements systems. The aimed of the present work was to investigate the influence of microrelief on the spatial variability of different particle-size fractions of the soils in the Apodi Plateau. A plano-altimetric survey was conducted in an area of 102 ha, followed by boreholes for collecting soil samples and determining the effective depth. The samples were subjected to particle-size analysis and the data processed with descriptive statistics and geostatistics, using semivariograms and kriging charts. Based on the microrelief, the study area was divided into 3 different surfaces (concave, convex and flat). From the results a clear influence of the microrelief on the distribution of the particle-size fractions was identified. Higher clay-content and greater soil depth were found on the concave surface. These results indicate greater soil-genesis activity in the soils of this area in response to the existing convergent water flows. The occurrence of higher levels of sand and shallower soils on the convex and more elevated surface indicates less soil-genesis activity and a greater intensity of the selective-erosion process. The use of geostatistics contributed to the identification of areas with different soilmanagement needs, serving as an important tool for decision making, especially when related to irrigation.
\end{abstract}

Key words: Apodi Plateau. Spatial Variability. Microtopography. Soil-analysis.

\footnotetext{
* Autor para correspondência

${ }^{1}$ Recebido para publicação em 01/06/2012; aprovado em 26/06/2013

Parte da Monografia de Graduação do primeiro autor; pesquisa financiada com recursos da Universidade Federal do Ceará-UFC, Banco do Nordeste do Brasil-BNB e CNPq

${ }^{2}$ Departamento de Ciências do Solo, Universidade Federal do Ceará/UFC, Campus do Pici, Bloco 807, Fortaleza-CE, Brasil, 60.455-760, daniel_ pontes78@hotmail.com

${ }_{3}^{3}$ Departamento de Ciências do Solo/UFC, Campus do Pici, Bloco 807, Fortaleza-CE, Brasil, 60.455-760, tiago@ufc.br, reromero@ufc.br, mirian.costa@ufc.br

${ }^{4}$ Departamento de Biologia Vegetal e Fitossanidade, Universidade Federal Rural da Amazônia/UFRA, Belém-PA, Brasil, 66.077-530, paulo. farias@pq.cnpq.br
} 


\section{INTRODUÇÃO}

A Chapada do Apodi, inserida no polígono das secas (LEMOS et al., 1997) e localizada na divisa dos estados do Ceará e do Rio Grande do Norte, destacase do semiárido circunjacente devido ao alto potencial agrícola oriundo da presença de solos calcários com boa fertilidade natural e presença de relevo plano, favorável à mecanização (BRASIL, 1973), além da disponibilidade de água do rio Jaguaribe, perenizado pelo Açude de Orós (MILHOME et al., 2009).

Devido à sua potencialidade agrícola, a região atrai o interesse econômico de investidores nacionais e internacionais, especialmente do ramo da fruticultura. A implantação de empreendimentos agrícolas na região vem dinamizando a economia local gerando emprego e renda para as populações adjacentes à Chapada. No entanto, as diferentes práticas agrícolas vêm gerando limitações no que diz respeito à manutenção e à sustentabilidade dos recursos naturais e, em especial, de seus solos (WEBER et al., 2006).

Os problemas desta área, de uma forma geral, estão ligados à utilização inadequada dos solos, em função da escassez de informações de base sobre esse recurso natural na Chapada do Apodi. Estudos prévios indicam os Cambissolos como a classe dominante na região (BRASIL, 1973), a qual é marcada por elevada variabilidade em suas propriedades químicas, físicas e mineralógicas em pequenas escalas espaciais (LEMOS et al., 1997), o que implica em solos de mesma classe taxonômica, porém com demandas de manejo distintas.

Estudos recentes (COSTA et al., 2011; OLIVEIRA et al., 2009) sugerem que esta variabilidade espacial dos atributos dos solos da Chapada do Apodi pode ocorrer em resposta a pequenas oscilações nas formas do relevo. De fato, Souza et al. (2006) ressaltam que alterações do microrrelevo podem alterar a dinâmica hídrica nos solos de uma área, condicionando a uma distribuição diferenciada de seus atributos.

Tendo em vista que a granulometria afeta sobremaneira o comportamento hídrico dos solos (GUI et al., 2010; PAZ-FERREIRO; VIDAR VÁZQUEZ; MIRANDA, 2010), em regiões semiáridas sua distribuição merece especial atenção, uma vez que, nesses locais, a irrigação é técnica comumente empregada para fins de aumento e, em alguns casos, de viabilização da produção agrícola. Diversos estudos recentes têm reforçado o papel da granulometria como atributo fundamental para o entendimento e modelagem de parâmetros hídricos associados aos fenômenos de movimento e retenção de água nos solos (ABBASI et al., 2011;CHAN; GOVINDARAJU, 2004; HWANG; CHOI, 2006).
Em face à homogeneidade dos demais fatores de formação de solos na região da Chapada do Apodi (BRASIL, 1973) partiu-se da hipótese de que o microrrelevo exerce influência na distribuição de partículas granulométricas nos solos da região. Sendo assim, o trabalho teve como objetivo avaliar a influência do microrrelevo na distribuição das frações granulométricas de solos desenvolvidos de calcário na Chapada do Apodi.

\section{MATERIAL E MÉTODOS}

O local de estudo compreende uma área de 102 ha, localizada no município de Limoeiro do Norte, na Chapada do Apodi, dentro dos domínios do estado do Ceará (Figura 1). O clima da região, segundo a classificação de Köppen, é do tipo BSw'h', caracterizado como muito quente e semiárido. A média pluviométrica da região é de $750 \mathrm{~mm}$ ano $^{-1}$ (BRASIL, 1973) e a evapotranspiração atinge média anual de $3.215 \mathrm{~mm}^{-1} \mathrm{ano}^{-1}$ (FERNANDES et al., 2005), caracterizando intenso déficit hídrico na região.

A Chapada do Apodi faz parte da bacia do Potiguar, cujas unidades estratigráficas são representadas predominantemente, pelos calcários da Formação Jandaíra no topo, com espessura variável podendo atingir um valor máximo da ordem de $600 \mathrm{~m}$, e pelos arenitos da Formação Açu, situados na base (PESSOA NETO et al., 2007).

Para caracterização do microrrelevo, realizou-se um levantamento planialtimétrico da área utilizando-se uma estação total (modelo Topcon) com precisão de 10" e alcance de $2 \mathrm{~km}$. Foram georreferenciados 52 pontos distribuídos no modelo de grade do tipo retangular de $200 \mathrm{~m}$ na linha e de $100 \mathrm{~m}$ entre linhas. Com base neste levantamento, foi gerado o Modelo de Elevação Digital (MED) no software Surfer 8.0, a partir do qual o relevo foi dividido em compartimentos, levando-se em consideração as curvaturas da superfície do terreno. A Figura 1 apresenta o MED, onde estão representadas as três superfícies (côncava, convexa e retilínea), bem como os vetores que simulam fluxo hídrico preferencial no local.

A diferença altimétrica identificada na área foi de $4 \mathrm{~m}$ ao longo dos 102 ha. Constatou-se que $97 \%$ do terreno apresenta declividade inferior a $3 \%$, enquanto que no restante da área a declividade varia entre 3 e $8 \%$, classificando o relevo como plano e suave ondulado (SANTOS et al., 2005). Neste trabalho considera-se como microrrelevo as variações de declividade compreendidas no intervalo de 0 a $8 \%$, baseado na classificação de relevo proposta por Santos et al. (2005).

Em cada ponto da grade estabelecida foram coletadas amostras de solos em três profundidades $(0,0$ - 
0,2; 0,2-0,4 e 0,4-0,6 m), totalizando 134 amostras (60 na superfície côncava, 43 na convexa e 31 na retilínea). Por ocasião das coletas para as determinações granulométricas, realizaram-se sondagens utilizando-se trado holandês para determinar a profundidade efetiva dos solos.

Depois de coletadas, as amostras foram secas ao ar, destorroadas e passadas em peneiras com malha de $2 \mathrm{~mm}$ para obtenção da terra fina seca ao ar (TFSA). Posteriormente, as amostras foram submetidas à análise granulométrica realizada pelo método da pipeta, utilizandose como dispersante químico o hexametafosfato de sódio e agitação rápida durante 10 minutos. A fração areia foi separada por tamização e a fração argila por sedimentação, seguindo a lei de Stookes (EMPRESA BRASILEIRA DE PESQUISA AGROPECUÁRIA, 1997).

Como forma inicial de avaliar os dados gerados em laboratório, os resultados foram submetidos à estatística descritiva, calculando-se medidas de localização (média e mediana), de variabilidade (desvio padrão e coeficiente de variação) e de tendência central (assimetria), para cada compartimento nas profundidades amostradas. Desta forma, avaliou-se a normalidade dos atributos (CRUZ et al., 2010) que, por se tratarem de dados oriundos da natureza, apresentam ajuste apenas aproximado a uma distribuição normal (WARRICK; NIELSEN, 1980).

A dependência espacial das amostras foi avaliada utilizando-se a geoestatística, fazendo-se uso da construção de semivariogramas, conforme a equação 1, de acordo com Vieira (2000):

$$
\gamma(\mathrm{h})=\frac{1}{2 \mathrm{~N}(\mathrm{~h})} \sum_{\mathrm{i}=1}^{\mathrm{N}(\mathrm{h})}\left[\mathrm{Z}\left(\mathrm{x}_{\mathrm{i}}\right)-\mathrm{Z}\left(\mathrm{x}_{\mathrm{i}}+\mathrm{h}\right)\right]^{2}
$$

onde $\gamma(\mathrm{h})$ é a semivariância estimada a partir de dados experimentais, $\mathrm{N}$ (h) é o número de pares experimentais de valores medidos $\mathrm{Z}(\mathrm{xi}), \mathrm{Z}$ (xi+h), separados por um vetor $h$.

Inicialmente foram realizadas análises variográficas que foram elaboradas para uma direção global isotrópica, ou seja, adotando-se um ângulo de tolerância de $90^{\circ}$. Com o intuito de definir os parâmetros variográficos, foram realizadas tentativas de ajustes aos modelos esférico, gaussiano e pentaesférico, com distâncias variadas entre os pares (OLIVEIRA et al., 2009).

Depois de gerados os semivariogramas e constatada a dependência espacial foram gerados mapas de isolinhas, utilizando-se como interpolador o método da Krigagem por meio do programa Surfer 8.0 (GOLDEN SOFTWARE INC., 1999).

A classificação do grau de dependência espacial (GD), relação entre o efeito pepita (Co) e o patamar $\left(\mathrm{Co}+\mathrm{C}_{1}\right)$, foi realizada segundo Cambardella et al. (1994). Para análise do coeficiente de variação (CV), utilizou-se a classificação proposta por Warrick e

Figura 1 - Localização da área de estudo (A), Modelo de Elevação Digital (MED) com os compartimentos do microrrelevo, os pontos de amostragem de solo e os vetores que simulam a direção dos fluxos hídricos na área (B)
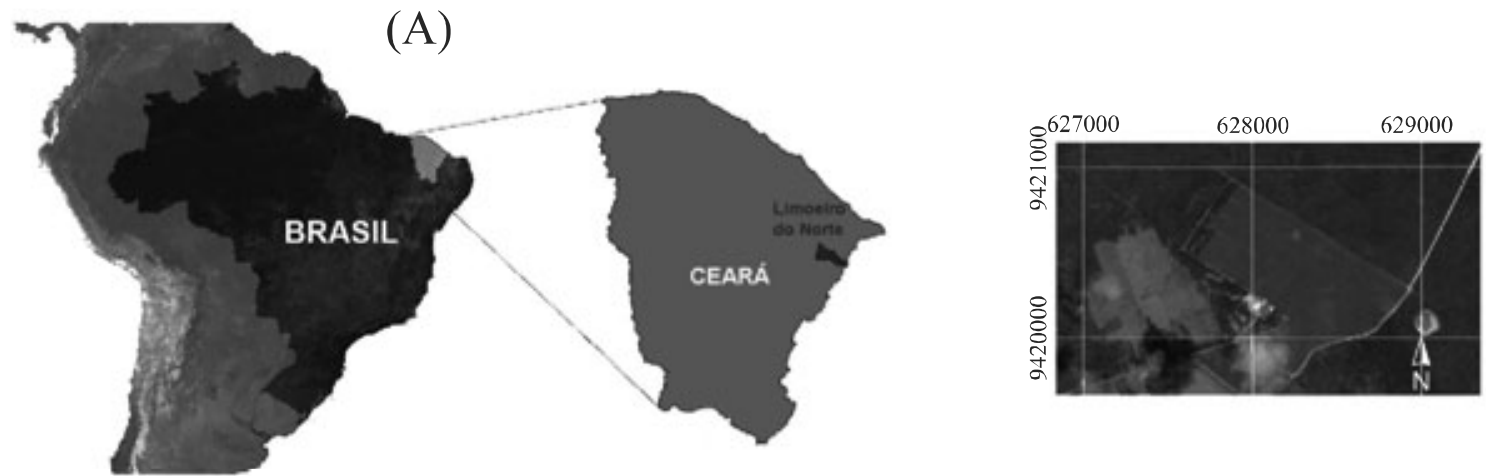

(B)

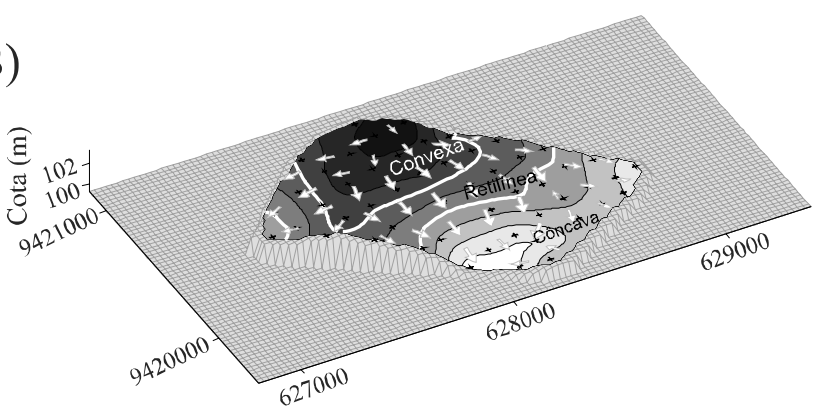


Nielsen (1980), sendo considerada: baixa: CV $<12 \%$; média: CV entre 12 e $60 \%$ e alta: $\mathrm{CV}>60 \%$.

A análise da distribuição dos dados foi feita com base na seguinte classificação de Vieira, Mello e Lima (2007): distribuição simétrica quando coeficiente de assimetria igual a zero $(\mathrm{CA}=0)$; distribuição assimétrica à esquerda quando $\mathrm{CA}>0$; e distribuição assimétrica à direita quando $\mathrm{CA}<0$.

\section{RESULTADOS E DISCUSSÃO}

Na Tabela 1 encontram-se os valores médios e a estatística descritiva das frações granulométricas dos diferentes compartimentos do microrrelevo e das diferentes profundidades estudadas. A proximidade entre os valores de mediana e média para os atributos granulométricos analisados indica que não há assimetria acentuada (LEÃO et al., 2010) e que, com a ocorrência de valores semelhantes, os dados se aproximam ou apresentam distribuição normal (LITTLE; HILLS, 1978).

Quanto ao coeficiente de variação (CV), também apresentado na Tabela 1, observa-se que os valores ficaram entre 12 e $60 \%$ sendo, portanto, classificado como médio (WARRICK; NIELSEN 1980). Os CVs mais elevados foram observados para argila e silte $(15,16$ a 46,23\%, Tabela 1$)$, enquanto que os menores para areia $(10,42$ a $37,36 \%$, Tabela 1$)$. Os maiores valores de CV para argila e silte indicam que, nos solos estudados, estas frações são mais passíveis de alteração, o que está de acordo com a classe dos Cambissolos presente na área (COSTA et al., 2011), a qual caracteriza-se por uma pedogênese pouco avançada e, portanto, pela maior presença de minerais alteráveis, tanto na fração argila (argilas 2:1), como na fração silte (EMPRESA BRASILEIRA DE PESQUISA AGROPECUÁRIA, 2006). De fato, segundo Vieira, Mello e Lima (2007), quanto menos intemperizado o material do solo maior é a variabilidade dos parâmetros estudados.

No caso da fração areia, cabe ressaltar que boa parte dessa fração é constituída por nódulos e concreções ferruginosas (petroplintita de tamanho entre 0,05 e $2 \mathrm{~mm}$ ) caracterizados por sua acentuada cimentação (EMPRESA BRASILEIRA DE PESQUISA AGROPECUÁRIA, 2006) e, portanto, alta estabilidade.

Quanto ao coeficiente de assimetria (CA), verificou-se que os valores de todas as variáveis tenderam a zero (Tabela 1). De acordo com esses resultados, as variáveis classificam-se como assimétricas, no entanto, como já discutido anteriormente, os dados tendem à normalidade, principalmente os que apresentam valores de CA inferiores a 1 (VIEIRA; MELLO; LIMA., 2007). De modo geral, os dados apresentam baixa distorção, reforçando sua tendência à normalidade.

De acordo com Cressie (1991), a análise geoestatística pode ser realizada com dados que não apresentam distribuição normal, porém, é fundamental que a distribuição não apresente caudas muito alongadas, o que poderia comprometer as análises. Desta forma, pode-se considerar que os dados do presente estudo foram suficientemente simétricos para um estudo geoestatístico (GONÇALVES; FOLEGATTI; MATA 2001).

Com a análise geoestatística (Tabela 2) das frações granulométricas do solo constata-se, por meio dos parâmetros dos semivariogramas, que os modelos que melhor se ajustaram aos dados foram o gaussiano, o pentaesférico e o esférico, variando em função da profundidade e da fração granulométrica. O modelo gaussiano foi o que melhor se ajustou ao atributo argila na primeira profundidade. Nas demais camadas, para a mesma variável, o melhor ajuste se deu com o modelo esférico. Para as variáveis areia e silte, o modelo pentaesférico foi o que melhor se ajustou nas duas primeiras profundidades; porém, na última o modelo esférico foi o que apresentou melhor ajuste para a fração areia.

Para a variável silte na camada de 0,4-0,6 m não foi observado estrutura de dependência espacial para a construção do semivariograma, premissa fundamental para construção do mapa de isolinhas.

A variação das classes de dependência pode ser observada na Tabela 2. Para a variável argila, observou-se que nas camadas de 0,0-0,2 e 0,2-0,4 $\mathrm{m}$ a dependência foi moderada, enquanto que para areia e silte a dependência foi forte.

Segundo Cambardella et al. (1994), uma dependência espacial forte dos atributos do solo pode ser atribuída a fatores inerentes ao solo, tais como material de origem e relevo, enquanto que uma dependência espacial fraca pode ser atribuída a fatores externos, como práticas de manejo.

Sendo assim, a predominância de classes de dependência espacial variando de forte a moderada neste estudo indica a influência do microrrelevo, uma vez que os solos da área são todos originados de calcário e que, no período de coleta das amostras, a área encontrava-se sob mata nativa e, ainda, o clima e o tempo são semelhantes na área.

Quanto ao alcance dos semivariogramas, os valores mais elevados foram encontrados para a variável 
Tabela 1 - Estatística descritiva das variáveis areia, silte e argila para a área de estudo nas profundidades de 0,0-0,2;0,2-0,4 e $0,4-0,6 \mathrm{~m}$

\begin{tabular}{|c|c|c|c|c|c|c|}
\hline \multirow{2}{*}{ Superfície } & \multirow{2}{*}{ Variável } & Média & Mediana & \multirow{2}{*}{ Desvio Padrão } & $\mathrm{CV}^{(1)}$ & \multirow{2}{*}{$\mathrm{CA}^{(2)}$} \\
\hline & & \multicolumn{2}{|c|}{-------------g kg-1-------------- } & & $\%$ & \\
\hline \multicolumn{7}{|c|}{ Profundidade $0,0-0,2 \mathrm{~m}$} \\
\hline \multirow{3}{*}{ Convexa } & Argila & 204,42 & 216,10 & 57,13 & 27,95 & $-1,23$ \\
\hline & Silte & 255,63 & 238,85 & 68,00 & 26,62 & 0,35 \\
\hline & Areia & 539,94 & 537,75 & 88,11 & 16,32 & 0,43 \\
\hline \multirow{3}{*}{ Retilínea } & Argila & 216,20 & 207,80 & 85,26 & 39,44 & $-0,06$ \\
\hline & Silte & 258,51 & 243,55 & 90,15 & 34,87 & $-0,17$ \\
\hline & Areia & 525,29 & 494,25 & 148,72 & 28,31 & 1,10 \\
\hline \multirow{3}{*}{ Côncava } & Argila & 309,81 & 318,20 & 97,65 & 31,52 & $-0,05$ \\
\hline & Silte & 322,95 & 317,40 & 78,46 & 24,27 & 0,92 \\
\hline & Areia & 367,24 & 351,00 & 123,96 & 33,76 & $-0,08$ \\
\hline \multicolumn{7}{|c|}{ Profundidade $0,2-0,4 \mathrm{~m}$} \\
\hline \multirow{3}{*}{ Convexa } & Argila & 264,60 & 261,60 & 40,12 & 15,16 & 1,24 \\
\hline & Silte & 251,65 & 250,95 & 63,63 & 25,28 & $-0,09$ \\
\hline & Areia & 483,75 & 474,75 & 50,42 & 10,42 & $-0,14$ \\
\hline \multirow{3}{*}{ Retilínea } & Argila & 259,00 & 221,80 & 119,73 & 46,23 & 0,31 \\
\hline & Silte & 255,65 & 247,00 & 101,14 & 39,56 & $-0,36$ \\
\hline & Areia & 485,35 & 423,50 & 167,06 & 34,42 & 1,32 \\
\hline \multirow{3}{*}{ Côncava } & Argila & 382,30 & 369,80 & 100,25 & 26,22 & $-0,15$ \\
\hline & Silte & 299,23 & 278,45 & 101,40 & 33,89 & 0,50 \\
\hline & Areia & 318,47 & 306,50 & 118,98 & 37,36 & 0,91 \\
\hline \multicolumn{7}{|c|}{ Profundidade $0,4-0,6 \mathrm{~m}$} \\
\hline \multirow{3}{*}{ Convexa } & Argila & 263,82 & 269,80 & 23,09 & 20,12 & 0,25 \\
\hline & Silte & 230,86 & 253,90 & 77,01 & 33,36 & 0,25 \\
\hline & Areia & 505,32 & 483,00 & 89,54 & 17,72 & 1,30 \\
\hline \multirow{3}{*}{ Retilínea } & Argila & 297,16 & 255,80 & 87,91 & 29,58 & 0,87 \\
\hline & Silte & 285,07 & 292,70 & 64,27 & 22,54 & $-0,72$ \\
\hline & Areia & 417,78 & 391,00 & 82,96 & 19,86 & 0,32 \\
\hline \multirow{3}{*}{ Côncava } & Argila & 392,24 & 405,40 & 99,65 & 25,41 & $-0,31$ \\
\hline & Silte & 278,62 & 266,60 & 73,31 & 26,31 & 0,61 \\
\hline & Areia & 329,15 & 323,50 & 115,64 & 35,13 & 0,50 \\
\hline
\end{tabular}

$\mathrm{CV}^{(1)}$ - Coeficiente de variação; $\mathrm{CA}^{(2)}$ - Coeficiente de assimetria

areia nas duas primeiras profundidades e para argila na camada de 0,2-0,4 m (Tabela 2). Cabe ressaltar que todos os valores de alcance foram superiores ao do espaçamento de amostragem (Tabela 2), indicando boa correlação entre as amostras, fato que favorece as etapas de interpolação dos dados (VIEIRA, 2000). Segundo
Souza et al. (2007), o alcance dos semivariogramas pode fornecer informações relevantes sobre a gênese de solos na paisagem, uma vez que as interpolações permitem melhor visualização dos padrões de distribuição espacial e, portanto, melhor compreensão dos fatores e processos mais ativos na pedogênese de determinado solo. 
Tabela 2 - Parâmetros dos semivariogramas ajustados às frações granulométricas das profundidades de 0,0-0,2; 0,2-0,4 e 0,4-0,6 m

\begin{tabular}{lccccccc}
\hline Atributo & Modelo & $\mathrm{Co}^{(1)}$ & $\mathrm{Co}+\mathrm{C}^{(2)}$ & $\mathrm{C}^{(3)}$ & $\mathrm{a}^{(4)}$ & $\mathrm{GDE} \%(5)$ & $\mathrm{CDE}^{(6)}$ \\
\hline Argila & Gaussiano & 2300 & 5500 & 3200 & 240 & 41,81 & moderada \\
Areia & Pentaesférico & 3100 & 18000 & 14900 & 470 & 17,22 & forte \\
Silte & Pentaesférico & 1300 & 6000 & 4700 & 340 & 21,66 & forte \\
\hline & & & & $0,2-0,4 \mathrm{~m}$ & & & moderada \\
\hline Argila & Esférico & 4000 & 8000 & 4000 & 450 & 50 & forte \\
Areia & Pentaesférico & 500 & 21600 & 21100 & 460 & 2,31 & forte \\
Silte & Pentaesférico & 1300 & 6000 & 4700 & 340 & 21,66 & \\
\hline Argila & & & & $0,4-0,6 \mathrm{~m}$ & & & forte \\
Areia & Esférico & 2000 & 8500 & 6500 & 300 & 23,52 & forte \\
\hline
\end{tabular}

${ }^{(1)} \mathrm{Co}$ - Efeito pepita; ${ }^{(2)} \mathrm{Co}+\mathrm{C}$ - Patamar; ${ }^{(3)} \mathrm{C}$ - Variância estrutural; ${ }^{(4)} \mathrm{a}$ - Alcance; ${ }^{(5)} \mathrm{GDE} \%$ - Grau de dependência espacial; ${ }^{\left({ }^{6}\right)} \mathrm{CDE}$ - Classe de dependência espacial (CAMB ARDELLA et al., 1994)

A partir dos parâmetros dos semivariogramas foram gerados os mapas de distribuição espacial das frações areia, silte e argila (Figura 2 a 4). Na Figura 2, verifica-se incremento nos teores de argila na superfície côncava (no sentido convexa $\rightarrow$ côncava). Nessa área, observa-se que as classes de textura do solo variaram de franca a argilosa (SANTOS et al., 2005). O padrão de distribuição da fração silte (Figura 3) foi semelhante ao da argila, apresentando também maiores teores na superfície côncava.

Contrariamente, a fração areia (Figura 4) apresentou distribuição espacial distinta em relação às frações argila e silte. Nas três profundidades os maiores teores de areia ocorreram na superfície convexa, predominando nessa superfície solos com textura franca (SANTOS et al., 2005).

Com os resultados têm-se indicativos de uma distribuição das partículas granulométricas influenciada pelo movimento diferenciado de água no solo, em resposta às distintas formas do microrrelevo.

De fato, por meio da simulação do mapa de vetores (Figura 1), identifica-se clara tendência de maior fluxo de água no sentido da superfície côncava. Sendo assim, a maior ação de fluxos hídricos convergentes nessa superfície (GESSLER et al., 2000) estaria favorecendo a intensificação das reações químicas do intemperismo sobre os minerais primários nas frações silte e areia, resultando em maior formação de argila in situ nessa superfície. Segundo Campos, Cardoso e Marques Júnior (2006), as formas de relevo podem exercer papel decisivo na intensidade e direção dos fluxos da água no terreno e, portanto, reger a
Figura 2 - Distribuição dos teores de argila $\left(\mathrm{g} \mathrm{kg}^{-1}\right)$ nas profundidades de $0,0-0,20 ; 0,20-0,40$ e $0,40-0,60 \mathrm{~m}$
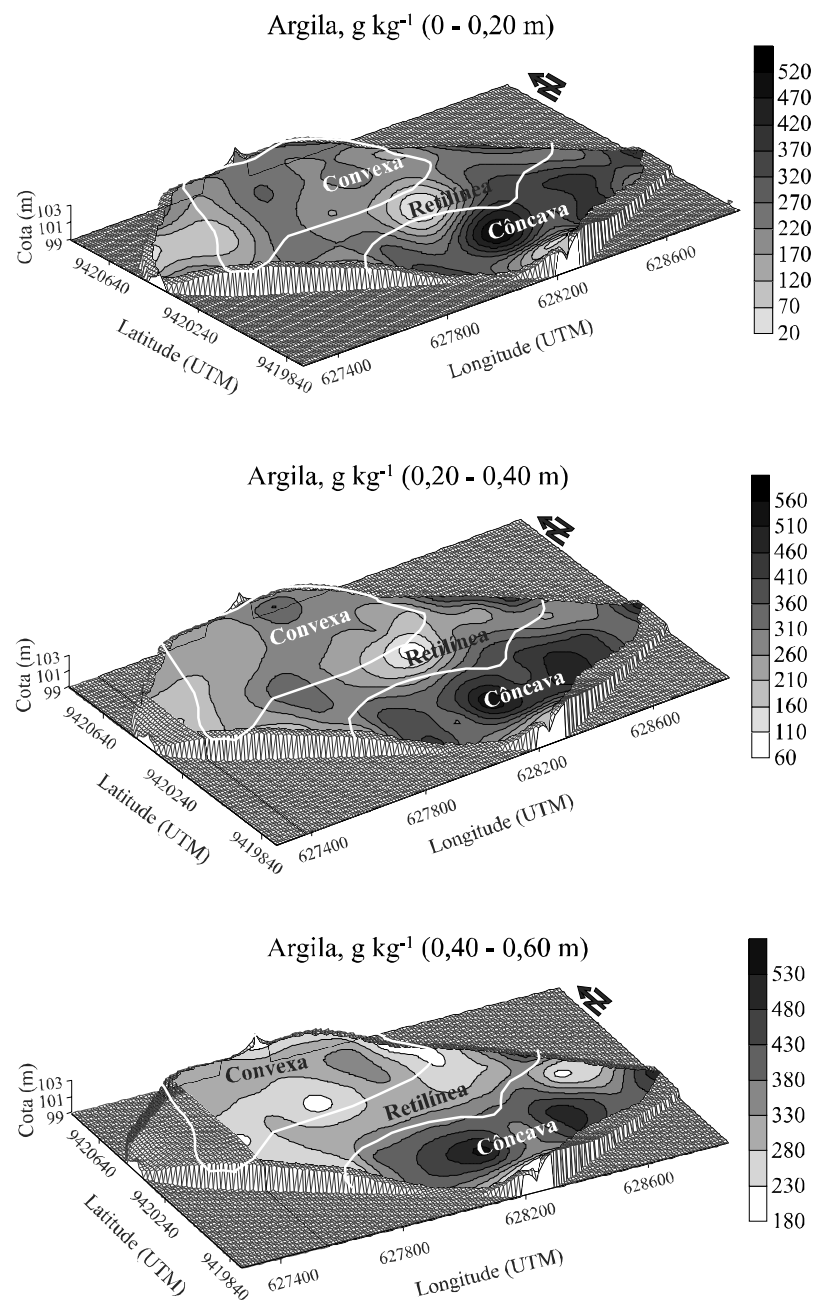
Figura 3 - Distribuição dos teores de silte $\left(\mathrm{g} \mathrm{kg}^{-1}\right)$ nas profundidades de $0,0-0,20$ e $0,20-0,40 \mathrm{~m}$
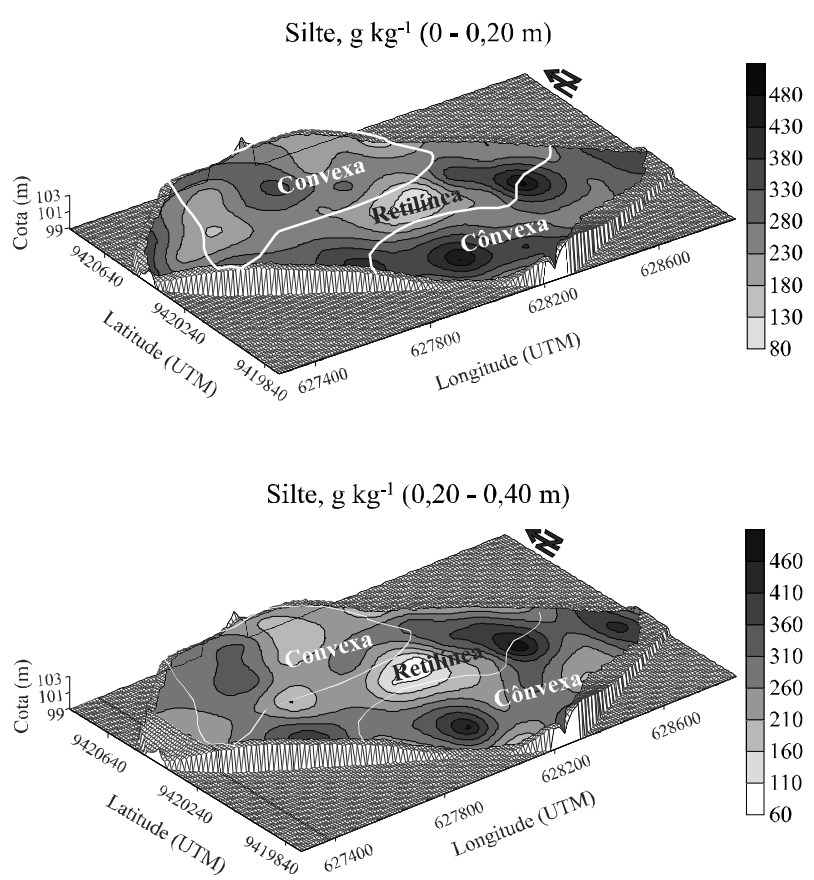

intensidade e direção dos processos pedogenéticos. Tais formas podem criar ainda rotas preferenciais para o fluxo hídrico causando, desta forma, variabilidade espacial nas propriedades do solo (SOUZA, 2001).

Por outro lado, na superfície convexa (Figura 1), onde os fluxos hídricos tendem a ser divergentes (GESSLER et al., 2000), a interação da água com o solo seria diminuída, desfavorecendo as alterações minerais e a dissolução do calcário.

Esta hipótese de alteração diferenciada nas distintas superfícies do terreno é corroborada pela distribuição da profundidade efetiva dos solos na área de estudo, que foi constatada pela presença de solos mais profundos na superfície côncava, indicando que o direcionamento dos fluxos hídricos pelo microrrelevo favorece maior alteração dos solos neste local (COSTA et al., 2011; OLIVEIRA, 2008).

Neste caso, o movimento hídrico lateral das porções mais altas (superfície convexa) para as mais baixas do terreno (superfície côncava) causaria a remoção preferencial de partículas finas (argila e silte) em suspensão para as porções mais rebaixadas. De fato, estudos recentes sugerem que a remoção preferencial de partículas finas da superfície consiste em uma das principais responsáveis pela formação de contrastes texturais em solos (PHILLIPS, 2004), inclusive em locais de relevo suave ondulado a plano
Figura 4 - Distribuição dos teores de areia $\left(\mathrm{g} \mathrm{kg}^{-1}\right)$ nas profundidades de $0,0-0,20 ; 0,20-0,40$ e $0,40-0,60 \mathrm{~m}$
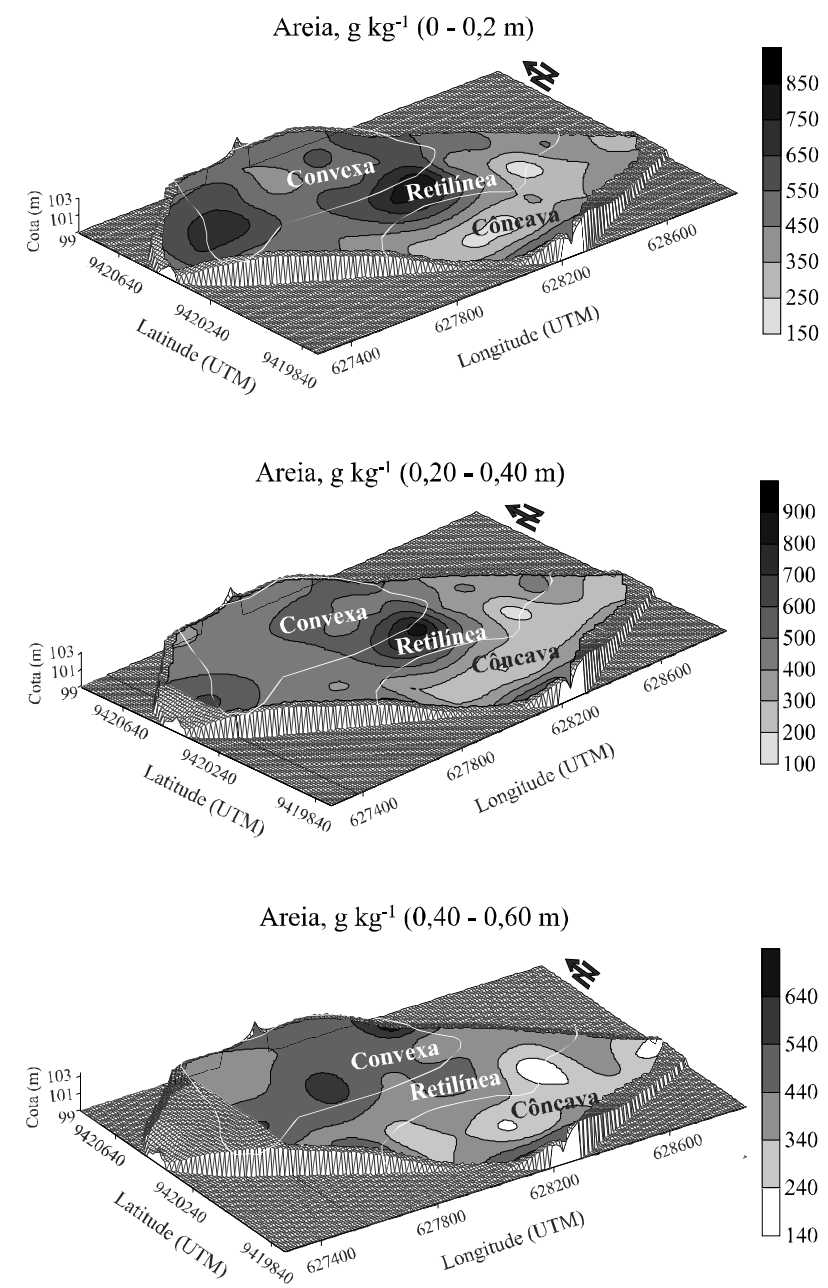

(OLIVEIRA et al., 2004). As correlações significativas entre elevação e argila $(\mathrm{r}=-0,576 ; \mathrm{n}=52 ; \mathrm{p}<0,0001)$ e elevação e $\operatorname{areia}(\mathrm{r}=0,671 ; \mathrm{n}=52 ; \mathrm{p}<0,000001)$, ambas referentes às amostras superficiais $(0,0-0,2 \mathrm{~m})$, corroboram esta hipótese (Figura 5).

Entretanto, deve-se ressaltar ainda que a distribuição diferenciada das partículas entre as superfícies pode ter sido influenciada por outros fatores, em associação ao microrrelevo, como por exemplo, a existência de fraturas no material de origem, favorecendo rotas hídricas preferenciais em determinados locais em detrimento a outros. De fato, em estudos realizados com solos desenvolvidos a partir de rochas calcárias, Liu et al. (2005) observaram que a indução de fluxos hídricos por meio de fraturas favoreceu a dissolução da rocha calcária, intensificando, nestes locais, a ação da pedogênese. 
Figura 5 - Correlações entre a elevação e os teores de argila e de areia na profundidade de $0-0,20 \mathrm{~cm}$

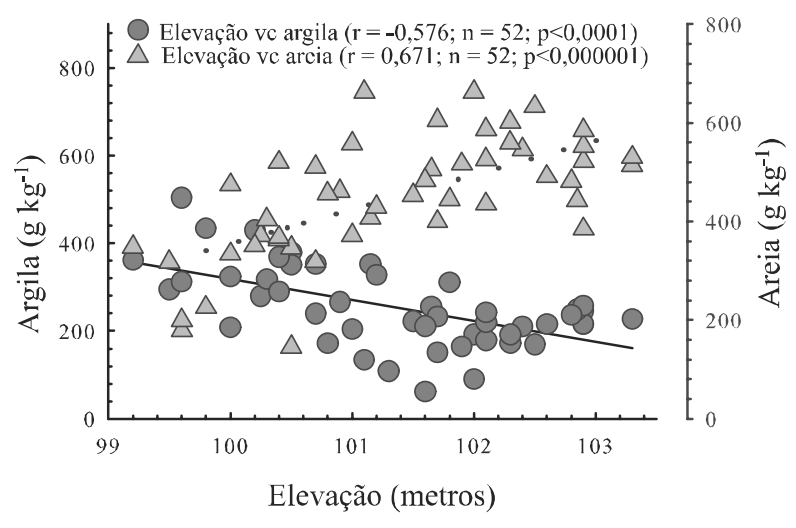

\section{CONCLUSÕES}

1. Os resultados evidenciam que a distribuição das frações granulométricas na área de estudo foi diretamente influenciada pelo microrrelevo, principalmente em resposta ao condicionamento de fluxos diferenciados de água ao longo das três superfícies;

2. Os maiores teores de argila na superfície côncava, associados à presença de solos mais profundos, podem indicar maior ação da pedogênese nos solos dessa porção do terreno em resposta à existência de fluxos hídricos preferenciais. Contrariamente, a existência de maiores teores de areia e solos mais rasos na superfície convexa e mais elevada indica menor ação da pedogênese dos solos e maior intensidade de remoção de partículas finas;

3. Neste sentido, o uso da geoestatística e de mapas a partir da krigagem contribuíram para a identificação de áreas que necessitam ser manejadas de forma diferenciada, servindo de importante ferramenta para a tomada de decisões, especialmente no que diz respeito ao manejo da irrigação, uma vez que a variabilidade de classes de texturas, causada pelas mudanças de microrrelevo, pode afetar o conteúdo de água no solo, sua condutividade hidráulica, assim como a suscetibilidade ao processo de salinização.

\section{AGRADECIMENTOS}

Ao CNPQ pela concessão de uma bolsa de iniciação científica ao primeiro autor na época da realização do trabalho. À empresa Agrícola Famosa pela concessão da área de estudo, e ao BNB pelo financiamento de parte do projeto. À Marcus Vinicius Chagas da Silva, M.Sc. em Geografia, pela ajuda na subdivisão da área em diferentes superfícies.

\section{REFERÊNCIAS}

ABBASI, Y. et al. Evaluation of pedotransfer functions for estimating soil water retention curve of saline and saline-alkali soils of Iran. Pedosphere, v. 21, n. 2, p. 230-237, 2011.

BRASIL. Ministério da Agricultura. Levantamento exploratório - reconhecimento de solos do Estado do Ceará. Recife, PE, 1973. v. 1.

CAMBARDELLA, C. A. et al. Field-scale variability of soil properties in Central Iowa Soil. Soil Science Society American Journal, v. 58, n. 5, p. 1501-1508, 1994.

CAMPOS, M. C. C.; CARDOSO, N. P.; MARQUES JUNIOR, J. Modelos de paisagem e sua utilização em levantamentos pedológicos. Revista de Biologia e Ciências da Terra, v. 6, n. 1, p. 104-114, 2006.

COSTA, M. C. G. et al. Profundidade do solo e micro-relevo em bananais irrigados: impactos na nutrição mineral e potencial produtivo. Revista Ciência Agronômica, v. 42, n. 3, p. 567578, 2011.

CHAN, T. P.; GOVINDARAJU, R. S. Estimating Soil Water Retention Curve from Particle-Size Distribution Data Based on Polydisperse Sphere Systems. Vadose Zone Journal, v. 3, n. 4, p. 1443-1454, 2004.

CRUZ, J. S. et al. Análise espacial de atributos físicos e carbono orgânico em Argissolo Vermelho-Amarelo cultivado com cana-de-açucar. Ciência e Agrotecnologia, v. 34, n. 2, p. 271-278, 2010.

CRESSIE, N. A. Statistics for spatial data. New York: John Wiley, 1991. $900 \mathrm{p}$.

EMPRESA BRASILEIRA DE PESQUISA AGROPECUÁRIA. Manual de métodos de análise de solo. Rio de Janeiro: EMBRAPA Solos, 1997. 212 p.

EMPRESA BRASILEIRA DE PESQUISA AGROPECUÁRIA. Sistema brasileiro de classificação de solos. 2. ed. Rio de Janeiro: EMBRAPA Solos, 2006. 306 p.

FERNANDES, M. A. B. et al. A origem dos cloretos nas águas subterrâneas na Chapada do Apodi-Ceará. Águas subterrâneas, v. 9, n. 1, p. 25-34, 2005.

GESSLER, P. E. et al. Modeling Soil-Landscape and Ecosystem Properties Using Terrain Attributes. Soil Science Society of America Journal, v. 64, n. 6, p. 2046-2056, 2000.

GOLDEN SOFTWARE INC. Surfer for windows: Realese 7.0, contouring and 3D surface mapping for scientist's engineers user's guide. New York, 1999. 619 p.

GONÇAlves, A. C. A.; FOLEGATTI, M. V.; MATA, J. D. V. da. Análises exploratória e geoestatística da variabilidade de propriedades físicas de um Argissolo Vermelho. Acta Scientiarum, v. 23, n. 5, p. 1149-1157, 2001.

GUI, D. et al. Ordination as a tool to characterize soil particle size distribution, applied to an elevation gradient at the north slope of the Middle Kunlun Mountains. Geoderma, v. 158, n. 3/4, p. 352-358, 2010. 
HWANG, S IL.; CHOI, S IL. Use of a lognormal distribution model for estimating soil water retention curves from particlesize distribution data. Journal of Hydrology, v. 323, n. 1/4, p. 325-334, 2006.

LEÃO, M. G. A. et al. Variabilidade especial da textura de um Latossolo sob cultivo de citros. Ciência e Agrotecnologia, v. 34, n. 1, p. 121-131, 2010.

LEMOS, M. S. S. et al. Evaluation of characteristics of cambisols derived from limestone in low tabelands in northeaster Brazil: Implications for management. Pesquisa Agropecuária Brasileira, v. 32, n. 8, p. 825-824, 1997.

LITTLE, T. M.; HILLS, F. J. Agricultural experimentation. New York: J. Wiley, 1978. 350 p.

LIU, J. et al. Dissolution-induced preferential flow in a limestone fracture. Journal of Contaminant Hydrology, v. 78, n. 1/2, p. 53-70, 2005.

MILHOME, M. A. L. et al. Avaliação do potencial de contaminação de águas superficiais e subterrâneas por pesticidas aplicados na agricultura do Baixo Jaguaribe, CE. Engenharia Sanitária e Ambiental, v. 14, n. 3, p. 363-372, 2009.

OLIVEIRA, D. P. de. et al. Geoestatística e modelo numérico de terreno em Ciências do Solo: estudo de caso na Chapada do ApodiCe. In: SIMPÓSIO BRASILEIRO DE SENSORIAMENTO REMOTO, 14., 2009, Natal. Anais... São José dos Campos: INPE, 2009. p. 4141-4147.

OLIVEIRA, J. B. de. Pedologia Aplicada. 3. ed. Piracicaba/SP: FEALQ,. 2008. 592 p.

OLIVEIRA, L. B. et al. Mineralogia, micromorfologia e gênese de solos planossólicos do sertão do Araripe, estado de Pernambuco. Revista Brasileira de Ciência do Solo, v. 28, n. 4, p. 665-678, 2004.

OLIVEIRA, P. C. G. et al. Variabilidade espacial de propriedades químicas do solo e da produtividade de citros na Amazônia Oriental. Revista Brasileira de Engenharia Agrícola e Ambiental, v. 13, n. 6, p. 708-715, 2009.

PAZ-FERREIRO, J; VIDAL VÁZQUEZ, E; MIRANDA, J. G. V. Assessing soil particle-size distribution on experimental plots with similar texture under different management systems using multifractal parameters. Geoderma, v. 160, n. 1, p. 47-56, 2010.
PESSOA NETO, et al. Bacia Potiguar. Boletim de Geociências, v. 15, n. 2, p. 357-369, 2007.

PHILLIPS, J. D. Geogenesis, pedogenesis, and multiple causality in the formation of texture-contrast soils. Catena, v. 58, n. 3, p. 275-295, 2004.

SANTOS, R. D. dos. et al. Manual de Descrição Coleta de Solo no Campo. 5. ed., Viçosa: Sociedade Brasileira de Ciências do Solo, 2005. 92 p.

SOUZA, Z. M. et al. Influência da variabilidade espacial de atributos químicos de um Latossolo na aplicação de insumos para agricultura de cana-de-açucar. Ciência e Agrotecnologia, v. 31, n. 2 , p. $371-377,2007$.

SOUZA, C. K. Relação solo-paisagem-erosão e variabilidade espacial de latossolos em área sob cultivo de cana-de-açúcar no município de Jaboticabal (SP). 2001. 186 f. Dissertação (Mestrado em Ciência do Solo) Faculdade de Ciências Agrárias e Veterinárias de Jaboticabal, Universidade Estadual Paulista, Jaboticabal, 2001.

SOUZA, Z. M. et al. Small relief shape variantions influence spatial variability of soils chemical attributes. Scientia Agricola, v. 63 , n. 2, p. 161-168, 2006.

VIEIRA, S. R. Geoestatística em estudos de variabilidade espacial do solo. In: NOVAIS, R. F.; ALVARES, V. H.; SCHAEFER, C. E. G. R. Tópicos em Ciência do Solo. Viçosa, MG: Sociedade Brasileira de Ciência do Solo, 2000. p. 1-54. v. 1 .

VIEIRA, V. A. S.; MELLO, C. R. de.; LIMA, J. M. Variabilidade espacial de atributos físicos do solo em uma microbacia hidrográfica. Ciência e Agrotecnologia, v. 31, n. 5, p. 14771485, 2007.

WARRICK, A. W.; NIELSEN, D. R. Spatial variability of soil physical properties in the field. In: HILLEL, D. (Ed). Aplications of soil physics. New York: Academic Press, 1980. cap. 2, p. 319-344.

WEBER, O. B. et al. Adubação nitrogenada e potássica em bananeira pacovan (Musa AAB, subgrupo prata) na Chapada do Apodi, Estado do Ceará. Revista Brasileira de Fruticultura, v. 28, n. 1, p. 154-157, 2006. 